\title{
Clinical and Sensorimotor Gating Effects of Ketamine in Normals
}

Erica J. Duncan, M.D., Steven H. Madonick, M.D., Arti Parwani, M.D., Burt Angrist, M.D., Rajive Rajan, M.D., Subhajit Chakravorty, M.D., Toby R. Efferen, M.A., Sandor Szilagyi, B.S., Myrsini Stephanides, Phillip B. Chappell, M.D., Stephen Gonzenbach, Ed.D., Grant N. Ko, M.D., and John P. Rotrosen, M.D.

The clinical similarities between PCP psychosis and schizophrenia have contributed importantly to the development of the glutamate hypothesis of schizophrenia. Sensory gating, as measured by prepulse inhibition of the acoustic startle reflex (PPI), is impaired in patients with schizophrenia. In animals, the noncompetitive NMDA antagonists PCP and ketamine disrupt PPI in a way that resembles the defect seen in schizophrenia. The purpose of this work is to investigate the modulation of sensory gating in humans by subanaesthetic doses of ketamine. 16 healthy male subjects received a 60-min infusion of ketamine $(0.5 \mathrm{mg} / \mathrm{kg})$ or normal saline on two separate days in a randomized double-blind crossover design. Clinical ratings and PPI were done during the infusion on both days. Ketamine produced robust clinical effects. Dissociative symptoms as measured by the CADSS increased from $0 \pm 0.0$ to $29.3 \pm 14.3$; negative symptoms (Affect Rating Scale) increased from $17.2 \pm 0.8$ to $24.8 \pm 3.1$; and total BPRS scores increased from $18.3 \pm 0.8$ to $26.4 \pm 5.1$. ANOVAs for these ratings were all significant at the $\mathrm{p}<.000$ level, although BPRS increases were not in the range seen in decompensated schizophrenic patients. The amplitudes of the startle responses to pulse-alone stimuli were not significantly different on ketamine and placebo days. Ketamine did not cause disruption in PPI as expected. On the contrary, in the first block of the PPI session ketamine significantly enhanced PPI ( $A N O V A ; F=6.15, \mathrm{p}=.026)$. These results indicate that the clinical effects of ketamine are not coupled with schizophrenic-like disruption of PPI in normal controls.

[Neuropsychopharmacology 25:72-83, 2001]

(C) 2001 American College of Neuropsychopharmacology. Published by Elsevier Science Inc.
KEY WORDS: Prepulse inhibition; Ketamine; Schizophrenia; Acoustic startle; Sensorimotor gating; Habituation

The clinical similarities between PCP psychosis and schizophrenia have contributed importantly to the development of the glutamate hypothesis of schizophrenia. PCP and ketamine bind to the PCP site in the chan-

From the Veterans Affairs New York Harbor Health Care System/New York Campus (EJD, BA, SC, TRE, SS, MS, SG, JPR, RR), New York, NY, New York University School of Medicine (EJD, SHM, AP, BA, JPR), New York, NY, Pfizer, Inc. (PBC, GNK), Groton, CT

Address correspondence to: Erica J. Duncan, M.D., Mental Health Service/116A, Atlanta Veterans Affairs Medical Center, 1670 Clairmont Road, Decatur, GA 30033, Tel.: (404) 321-6111 ext 7532, Fax: (404) 329-4643, email: eduncanmd@aol.com

Received June 12, 2000; revised November 5, 2000; accepted November 13, 2000. nel of the NMDA receptor complex, resulting in noncompetitive inhibition of NMDA type neurotransmission (Javitt and Zukin 1990). This induces a transient state in normals characterized by positive and negative symptoms and cognitive dysfunction which is similar to what is commonly observed in schizophrenics (Luby et al. 1959; Davies and Beech 1960; Bakker and Amini 1961; Allen and Young 1978; Krystal et al. 1994; Malhotra et al. 1996; Adler et al. 1999). Schizophrenics in remission experience a resurgence of symptoms characteristic of their decompensation when given ketamine (Ban et al. 1961; Itil et al. 1967; Lahti et al. 1995; Malhotra et al. 1997). The glutamate hypothesis of schizophrenia, which stems in part from the above findings, posits that a hypofunction of glutamatergic activ- 
ity contributes to the pathophysiology of this illness (Kim et al. 1980; Deutsch et al. 1989; Javitt and Zukin 1991; Olney and Farber 1995).

The acoustic startle response (ASR) is mediated by a simple three-synapse pathway (Davis 1997). The ASR is inhibited when the startling stimulus is preceded by a lower amplitude nonstartling prestimulus, a phenomenon termed prepulse inhibition (PPI)(Graham 1975). PPI is modulated by a number of sites, including the hippocampus (Swerdlow et al. 1993), which is heavily dependent on NMDA neurotransmission (Grunze et al. 1996).

Deficits in sensorimotor gating have been proposed to be linked to the symptoms of cognitive fragmentation, sensory flooding, and thought disorder (McGhie and Chapman 1961; Braff and Geyer 1990). Schizophrenics have impairments in PPI (Braff et al. 1978; Braff et al. 1992; Grillon et al. 1992; Bolino et al. 1994; Parwani et al. 2000). PPI is similarly impaired in animals following treatment with the NMDA antagonists PCP, MK-801, or ketamine (Mansbach and Geyer 1989; Mansbach 1991; Keith et al. 1991; Swerdlow et al. 1993; Johansson et al. 1995; al-Amin and Schwartzkopf 1996). However, PPI changes in animals treated with ketamine appear to be variable depending on timing and dose of ketamine administered (Mansbach and Geyer 1989; Mansbach 1991; Johansson et al. 1995; Swerdlow et al. 1998; de Bruin et al. 1999).

To date, there has been one published clinical study investigating the effects of ketamine on PPI in normals. van Berckel et al. (1998) found that low dose ketamine did not affect PPI. However, their PPI paradigm used a fixed interstimulus interval between prepulse and pulse stimuli.

We administered a ketamine challenge at a higher dose to normals, using a paradigm with varied interstimulus intervals, to investigate whether the resultant positive and negative symptoms would be accompanied by a gating deficit resembling that seen in schizophrenia.

\section{METHODS}

\section{Subjects}

Sixteen normal male volunteers (mean age $=33.3 \pm 3.1$ ) were recruited by means of local advertising at the Veterans Administration New York Harbor Medical Center (VAMC) and New York University Medical Center. The subjects signed informed consent forms which had been approved by the University IRB and the VAMC. All subjects were screened using the SCID -NP for Axis I and Axis II to rule out any psychiatric disorder. Additionally, the Wisconsin Psychosis Proneness Scale (Chapman et al. 1978) was administered to rule out any schizotypal personality traits. The exclusion criteria also included screening for psychiatric disorders in the subjects' first degree relatives, history of any medical or neurological illness, history of loss of consciousness, and history of any drug or alcohol dependence. All subjects were screened for intact hearing using an audiometer (Grason-Stadler, Model GS1710). Subjects were right-handed as determined by the Handedness Inventory.

\section{Ketamine Administration}

The study followed a double-blind cross-over design, with each subject receiving both a ketamine infusion and a placebo (saline) infusion on two separate days. The order of placebo and ketamine days was randomized with a mean interval of eight days between testing (range 4-21 days). Seven subjects received ketamine on Day 1 and saline on Day 2; nine subjects were randomized to the opposite medication order. The subjects were instructed to abstain from alcohol and other drug use for 24 hours preceding the study. Subjects reported to the startle laboratory at $8 \mathrm{AM}$ after an overnight fast.

Thirty minutes prior to infusion, an indwelling venous catheter was placed in the right forearm. Subjects received either saline $(0.9 \%$ sodium chloride) or ketamine hydrochloride $(0.5 \mathrm{mg} / \mathrm{kg})$ infused over a 60 minute period. Blood pressure and pulse were measured $30 \mathrm{~min}$ prior to infusion, and again at the 20,50, 90 , and 120 minute timepoints after the beginning of the infusion.

\section{Behavioral Ratings}

Behavioral changes were assessed with the Brief Psychiatric Rating Scale (BPRS)(Guy 1976), the Abrams and Taylor Rating Scale for Emotional Blunting (Abrams and Taylor 1978), and the Affect Rating Scale (Andreasen 1979). Perceptual changes were assessed with the Clinican-Administered Dissociative States Scale (CADSS), a 27-item scale designed to assesses five symptom domains: body perception, time perception, environmental perception, feelings of unreality, and memory impairment (Bremner et al. 1998). Anger, anxiety, drowsiness, highness, sadness, and feelings of interpersonal closeness were assessed by using subject rated $100 \mathrm{~mm}$ line visual analog scales. Subjects were evaluated using all the above scales 15 min before ketamine/placebo administration, 20 and 50 minutes into the infusion, and $30 \mathrm{~min}$ following the termination of the infusion (90- minute time point). Mental status ratings were conducted in a double-blind fashion by a single research clinician (AP, ED, SM, or $\mathrm{BA})$. All ratings 
on both study days for a given subject were carried out by a single rater.

\section{Startle Response Measurement}

The methodology for startle response measurement follows that of Braff et al. (1992), and is similar to the methods reported in Parwani et al. (2000). Immediately after catheter insertion, each subject's right eye was prepped and two disc electrodes (Ag-AgCl; impedance less than $6 \mathrm{Kohm}$ ) were positioned over the orbicularis oculi muscle, approximately $5 \mathrm{~mm}$ below the right eyelid, one directly below the pupil and the second approximately $5 \mathrm{~mm}$ lateral to the first. A third electrode was placed behind the right ear over the mastoid to serve as a ground. The acoustic startle session was administered starting 20 minutes after the beginning of the ketamine/placebo infusion and continued for 15 minutes. Subjects were seated comfortably in a chair and asked to gaze straight ahead at a picture positioned on a wall facing the subject. They were told that they could think of whatever they wished and did not have to attend specifically to the acoustic stimuli.

All acoustic stimuli were delivered binaurally through headphones (Maico,TDH-39-P). The startle session began with a three minute acclimation period consisting of $70 \mathrm{~dB}(\mathrm{~A})$ broadband noise, which continued as the background noise throughout the session. The pulse-alone stimulus was a $116 \mathrm{~dB}(\mathrm{~A}), 40 \mathrm{msec}$ duration burst of $1000 \mathrm{~Hz}$ pure tone with a near instantaneous rise time. The prepulse stimuli were $85 \mathrm{~dB}(\mathrm{~A}) 20 \mathrm{msec}$ bursts of pure tone, also at $1000 \mathrm{~Hz}$, presented 30, 60, and $120 \mathrm{msec}$ prior to the startle stimulus. The startle session consisted of 36 startle stimuli comprised of three blocks of 12 trials each. Each block consisted of three pulse-alone trials plus three trials of pulse with prepulse at each of the three designated prepulse intervals(30, 60, and $120 \mathrm{msec})$, presented in a pseudorandom order. Each session began with an initial pulsealone trial. Inter-trial intervals were 11-45 sec (average $26 \mathrm{sec}$ ) occurring in randomized order.

The eyeblink component of the acoustic startle response was measured via EMG of the right orbicularis oculi muscle. EMG activity was filtered $(1-500 \mathrm{~Hz})$, amplified, digitized by using a computerized EMG startle response monitoring system (SR-LAB, San Diego Instruments) and recorded in 2501 -msec readings from pulse onset. Digital signals were smoothed by an averaging paradigm that calculates a rolling average of the digital signals whereby the number of digital signals averaged is 10 . Startle amplitude was recorded in terms of digital units, where each digital unit equals $1.221 \mathrm{mi}-$ crovolts. Latencies are reported in milliseconds. The onset latency is defined by a shift of 6-digit units from the baseline value, occurring 21 to 120 milliseconds after the pulse-alone stimulus. Peak latency is defined as the point of maximal amplitude occurring within 150 milliseconds from the pulse-alone stimulus. Trials were rejected because of unstable EMG activity during the first $20 \mathrm{msec}$ or failure to reach peak amplitude within 95 msec of onset latency.

\section{Statistical Analysis}

Behavioral data were analyzed by using repeated measures analyses of variance (ANOVAs) with time and drug condition as within subjects factors. When the ANOVA drug $\times$ time interactions were significant, post hoc multiple comparisons of post-infusion time points to placebo/baseline were conducted by using Student Neuman-Keuls t-tests. Dependent measures for the startle reflex included startle amplitude, onset and peak startle latency, reflex habituation, and PPI. The latter was examined using both difference scores (amplitude difference between pulse-alone and prepulse + pulse trials) and percentage scores (calculated as the difference between the average pulse-alone and prepulse amplitudes, divided by the average pulse-alone amplitude for each block and multiplied by 100). Various ANOVA models were used to examine differences in startle amplitude, percent inhibition, and onset and peak latency with respect to the factors of drug (2 levels: placebo vs. ketamine), block (3 levels), and prepulse condition (4 levels: pulse-alone, $30 \mathrm{msec}$ prepulse, $60 \mathrm{msec}$ prepulse, and $120 \mathrm{msec}$ prepulse). Correlations between the changes in behavioral measures and the changes in startle data at the time of peak drug effect $(+50$ minutes) as well as between startle amplitude and prepulse inhibition were conducted using Spearman Rank Correlations. One subject was classified as a nonstartler (mean startle amplitude on the pulse-alone trials in block 1 (saline infusion day) was below 25 units) and was therefore excluded from the subsequent analyses.

\section{RESULTS}

\section{Behavioral Effects}

Pulse and Blood Pressure. Pulse rate as well as systolic and diastolic blood pressure increased during ketamine infusion but not during saline (ANOVA, pulse, Drug: $p=.002$; ANOVA, systolic blood pressure, Drug: $p<.0001$; ANOVA, diastolic blood pressure, Drug: $p<$ .0001) (see Table 1). None of these changes were clinically significant.

Brief Psychiatric Rating Scale. Ketamine produced highly significant increases in total BPRS score (Table 1). (ANOVA, Drug: $p<.0001$ ). There were no significant differences in baseline scores between test days. BPRS scores returned to baseline within 30 minutes following the termination of ketamine infusion. 


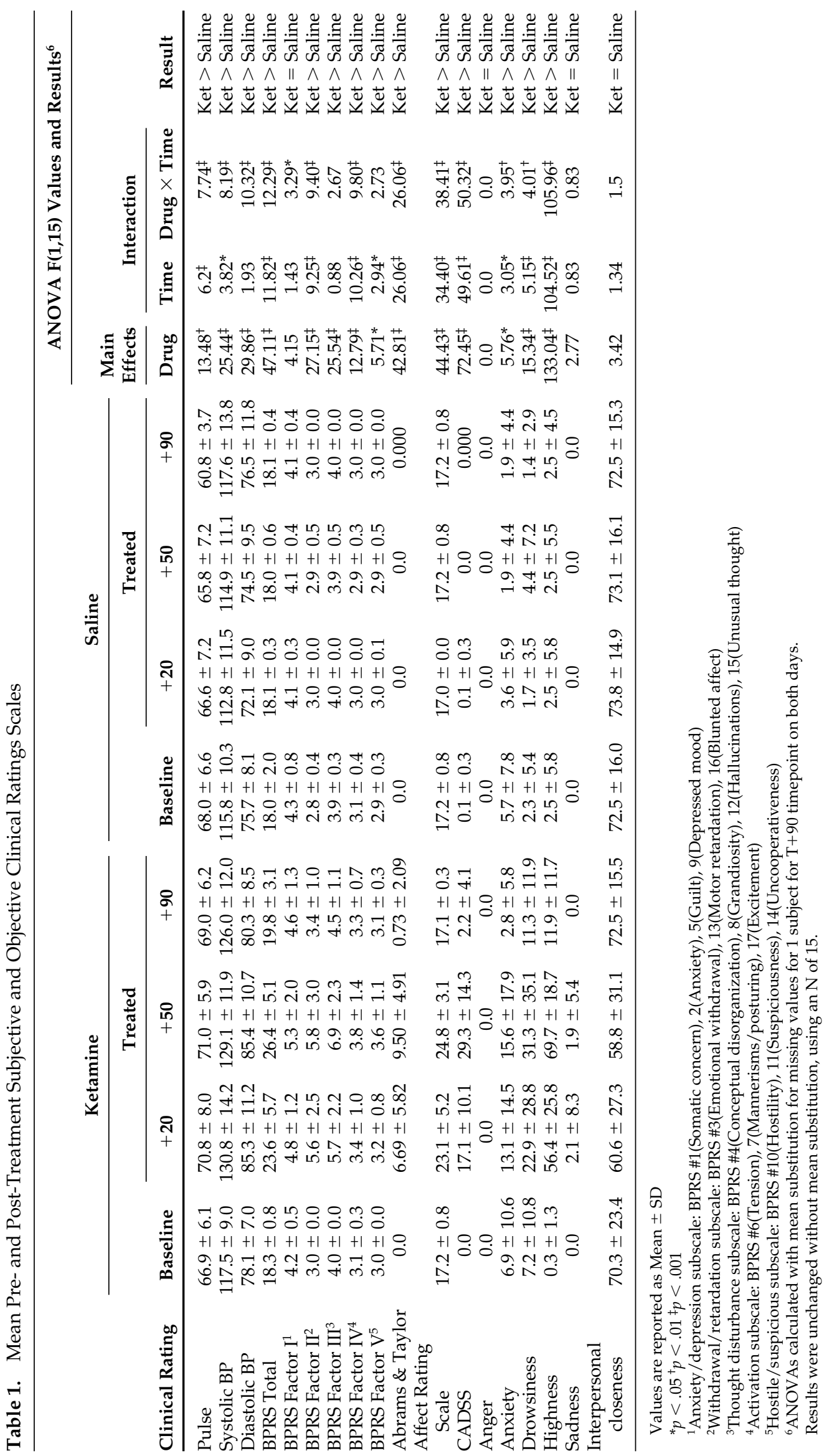


Some BPRS subfactors also showed robust increases on the ketamine day (Table 1). The Thought Disturbance subfactor showed highly significant increases on ketamine (ANOVA, Drug: $p<.0001$ ), as did the Withdrawal Retardation subfactor (ANOVA, Drug: $p<.001$ ) and the Hostility/suspiciousness subscale (ANOVA, Drug: $p<.03$ ). Post hoc Neuman-Keuls t-tests of both the total BPRS score and the subscales revealed significant increases from baseline $(p<.001)$ at 20 and $50 \mathrm{~min}$ following the initiation of ketamine infusion. Placebo treatment did not result in significant increases in BPRS scores from baseline. Individual data on the ketamine day showed that 13 out of the 16 subjects $(81 \%)$ had increases from baseline in the Thought Disturbance subscale, 12 of $16(75 \%)$ had increases in the WithdrawalRetardation subscale; 10 of $16(63 \%)$ had increases in the Anxiety-Depression subscale, 6 of $16(38 \%)$ had increases in the Hostility-Suspiciousness subscale, and 5 of $16(31 \%)$ had increases in the Activation subscale. There were no increases in these subscales on the saline day.

Negative symptoms scales. Ketamine significantly increased affective flattening as measured by the Affect Rating Scale (Table 1). (ANOVA, Drug: $p<.0001$ ). There were no changes in the items in this scale measuring affective overreactivity for any subject. Ketamine significantly increased negative symptoms from baseline both at the 20 and $50 \mathrm{~min}$ timepoints. Placebo did not elicit significant increases from baseline at any time point. Emotional blunting as measured by the Abrams and Taylor Scale was similarly increased by ketamine (ANOVA, Drug: $p<.0001$ ).

Perceptual Alterations. Perceptual alterations, as measured by the CADSS, were robustly increased by ketamine at the 20 and $50 \mathrm{~min}$ infusion points as revealed by ANOVA $(p<.0001)$ (Table 1$)$.

Visual Analog Scales of Mood States. Ketamine significantly increased anxiety, highness, and drowsiness as assessed by the $100 \mathrm{~mm}$ line visual analog scales of mood states. There were no significant changes in anger or sadness (Table 1). (ANOVA, anxiety: $p<.05$; highness: $p<.0001$ ); drowsiness: $p<.001)$; anger: $p=1.0$; sadness: $p=.12$ ). The visual analog scale assessing interpersonal closeness showed a trend level decrease of $p=.08$.

Description of ketamine phenomenology. Ketamine produced very robust clinical effects, some of which were most fully elicited during a debriefing interview after the effects of the drug had waned. Visual perceptual distortions were the most frequently reported, with subjects describing moving images or objects (the rocks in the picture [on the wall] "seem to be breathing," the mountains "look like faces"). Examiners were often perceived as being "robots" or "cartoon-like." Some sub- jects described a sensation of visual field narrowing ("tunnel vision") and others had a feeling that everything was in slow motion. Subjects described things in the environment as being "in and out of focus...like being on a merry-go-round, not dizzy but disoriented." Colors and lights appeared intensified and space and depth were "distorted," "seen in 2-D." Changes in the tones of people's voices and hypersensitivity to the startle stimuli were also described by some subjects. One subject perceived the background noise of the startle apparatus as "music coming from a stereo system." Two subjects became suspicious of being overmedicated with ketamine. Two others had hyperacusis which led to paranoia with referential thinking about the conversations of people in the adjoining room.

During ketamine infusion, subjects appeared muted and withdrawn. In the debriefing interview they subsequently described feeling that it took "too much effort" to sustain interpersonal interactions. They felt it was difficult to do things, as though they had to "think about moving or talking." Mood states were described as "profoundly neutral." One subject described feeling "introverted" while many subjects reported a lack of motivation, or a sense of indifference to things happening around them. Subjects often described experiencing "some kind of barrier" ("styrofoam", "a thick haze") between themselves and the examiner. Several of the subjects commented that they would not care about seeing their loved ones in their current state or would not care if they heard their favorite music while under the effects of ketamine.

During ketamine infusion subjects frequently reported an increased disorganization of thinking. One subject described this as "my thoughts are like holding a garden hose in the middle and it's spewing everywhere out of control." Subjects consistently had difficulty putting thoughts into words, and ketamine treated subjects appeared to be struggling to describe the feeling states induced by ketamine: "I'm trying to talk but nothing comes out of my mind." The thinking disturbance induced by ketamine was characterized both by poverty of content and concreteness. Many subjects demonstrated an inability to respond to proverbs with meaningful associations. For example, in response to the proverb "the tongue is the enemy of the neck" one subject commented "the tongue might hurt you, I just keep thinking of the tongue moving... it can't go any farther around."

Abnormal bodily sensations were commonly reported: "feels like I'm moving through a gel," in "viscous fluid." Feelings that the extremities did not belong to the body or to the subject himself were commonly described, and subjects were frequently observed moving their fingers, looking at their hands, touching their legs, etc. Other subjects reported that their bodies felt strange and distorted ("my head is a giant balloon"), 
and these feelings were usually coupled with changes in tactile sensations (i.e. heaviness of the limbs, paresthesias). Many subjects experienced numbness of various parts of their bodies, which is consistent with the analgesic effects of ketamine.

Subjects frequently described themselves as being "detached," with feelings of depersonalization and a sense of unreality. At the time of peak drug effect, one subject stated, "it feels like I'm looking out through an armor suit visor....my soul has shrunk inward, farther away from my body." Somatic sensations of "floating" and "out of the body" feelings were frequently described. Other subjects in the study described these sensations as "a hollow feeling inside," and "my legs are far away...I feel dissociated...like I'm not really here." Of the two subjects that vomited during the infusion, one reported that he felt curiously detached from the sensation of nausea and physical discomfort experienced during the episode.

The ketamine-induced high was described as a sense of "giddiness" or feeling "spaced out" which some subjects described as being similar to but not identical with the intoxicating effects of marijuana and nitrous oxide. A few subjects partially likened the high to feeling "a little drunk."

Other clinical effects. One subject developed ataxia which became apparent when he tried to walk at the conclusion of the ketamine infusion. A decreased sense of subjective coordination and proprioception was frequently reported. Nausea/vomiting occurred in two subjects, and the ketamine-induced emesis in one subject was repeated and severe. For this latter subject, nausea persisted for approximately one hour post-infusion. For other subjects, aside from a sense of fatigue which was reported by a few subjects to last for several hours after the infusion, ketamine treatment did not have any prolonged adverse effects. By 30 minutes post-infusion (+90 minute timepoint), all subjects had returned to their baseline mental status.

\section{Acoustic Startle}

Startle Amplitude. The mean amplitudes of the acoustic startle responses elicited by the pulse-alone and prepulse+ pulse trials in Block 1 are presented in Table 2 .

Amplitude to pulse-alone trials was first analyzed separately. The initial reactivity to the first pulse-alone stimulus was not significantly different between the ketamine and saline days $(\mathrm{F}(1,14)=.40, p=.54)$. There were no significant differences in startle response amplitude between ketamine and saline across the three blocks of the session (ANOVA: $p=.32$ ). There was robust habituation to pulse-alone startle across the session with both drugs (ANOVA: $p=.003$ ). Ketamine

Table 2. Acoustic Startle Data for Ketamine vs Saline Days ${ }^{1}$

\begin{tabular}{|c|c|c|c|c|c|c|}
\hline & \multirow[b]{3}{*}{ Ketamine } & \multirow[b]{3}{*}{ Saline } & \multicolumn{4}{|c|}{ ANOVA F Values and Results } \\
\hline & & & \multicolumn{2}{|c|}{ Main Effects(1,14) } & \multirow{2}{*}{$\frac{\text { Interaction }}{\text { Drug } \times \text { Block }}$} & \multirow[b]{2}{*}{ Result } \\
\hline & & & Drug & Block & & \\
\hline \multicolumn{7}{|c|}{ Pulse-alone startle } \\
\hline Block 1 & $236.0 \pm 170.3$ & $220.0 \pm 103.2$ & 1.09 & $7.41^{\dagger}$ & $6.41^{\dagger}$ & Ketamine $=$ Saline Habituation \\
\hline Block 2 & $166.0 \pm 126.9$ & $218.5 \pm 119.1$ & & & & \\
\hline \multirow[t]{2}{*}{ Block 3} & $159.4 \pm 119.8$ & $179.6 \pm 74.9$ & & & & \\
\hline & & & Drug & Trial Type & Drug $\times$ Trial Type & \\
\hline \multicolumn{7}{|l|}{ PPI-Block 1} \\
\hline $30 \mathrm{msec}$ & $52.2 \pm 36.8$ & $37.0 \pm 37.0$ & $6.15^{*}$ & $6.52^{+}$ & 0.36 & Ketamine $>$ Saline \\
\hline $60 \mathrm{msec}$ & $48.6 \pm 36.8$ & $43.7 \pm 26.6$ & & & & \\
\hline $120 \mathrm{msec}$ & $48.5 \pm 36.7$ & $48.7 \pm 33.0$ & & & & \\
\hline \multicolumn{7}{|c|}{ Onset Latency-Block 1} \\
\hline Pulse alone & $40.1 \pm 7.3$ & $36.5 \pm 5.1$ & $11.30^{+}$ & $10.92^{\ddagger}$ & 1.41 & Ketamine $>$ Saline $^{2}$ \\
\hline $30 \mathrm{msec}$ & $33.7 \pm 8.5$ & $30.3 \pm 6.8$ & & & & Latency facilitation \\
\hline $60 \mathrm{msec}$ & $37.5 \pm 8.8$ & $34.5 \pm 6.2$ & & & & \\
\hline $120 \mathrm{msec}$ & $41.2 \pm 8.4$ & $38.2 \pm 5.7$ & & & & \\
\hline \multicolumn{7}{|c|}{ Peak Latency-Block 1} \\
\hline Pulse alone & $65.2 \pm 6.4$ & $66.1 \pm 8.3$ & 2.07 & $9.55^{\ddagger}$ & 0.82 & Ketamine $=$ Saline ${ }^{2}$ \\
\hline $30 \mathrm{msec}$ & $51.4 \pm 7.9$ & $51.7 \pm 4.3$ & & & & Latency facilitation \\
\hline $60 \mathrm{msec}$ & $56.5 \pm 8.0$ & $54.6 \pm 7.4$ & & & & \\
\hline $120 \mathrm{msec}$ & $55.6 \pm 5.4$ & $57.1 \pm 6.3$ & & & & \\
\hline
\end{tabular}

${ }^{1}$ Values are reported as Mean $\pm \mathrm{SD}$

${ }^{2}$ ANOVA performed on data from Blocks $1-3$ with d.f. of 1,8

${ }^{*} p<.05^{+} p<.01{ }^{\ddagger} p<.001$ 
was associated with more rapid habituation (Drug $\times$ Block interaction: $p=.005$ )(Table 2).

An ANOVA was performed on pulse-alone amplitude using Day rather than Drug as a factor to assess possible order effects. In this model there was no effect of Day $(\mathrm{F}(1,14)=1.07, p=.32)$.

The data was next approached by means of a repeated measures ANOVA on raw amplitudes of all 36 trials, with drug (2 levels: ketamine and placebo), block (3 levels), and trial type (4 levels: pulse-alone, and 30, 60 , or $120 \mathrm{msec}$ interstimulus interval). Startle amplitude across all four trial types was lower on ketamine at a trend level $(\mathrm{F}(1,14)=3.81, p=.07)$. PPI was confirmed as indicated by a significant main effect for Trial Type $(\mathrm{F}(3,42)=27.62, p<.0001)$.

Prepulse Inhibition as Difference Score. PPI as a difference score was computed as (pulse-alone amplitude) - (prepulse+pulse amplitude) for each of the prepulse trial types in each block. There were no differences between ketamine and saline when ANOVAs were performed on the three blocks together $(\mathrm{F}(1,14)=.02, p=$ .9) or on Block 1 alone $(\mathrm{F}(1,14)=.84, p=.4)$.

Percent Prepulse Inhibition. Percent PPI was computed as $100 \times$ (pulse-alone amplitude - prepulse + pulse amplitude) / pulse-alone amplitude. When the three blocks and the three trial types of each session were analyzed together, there was a weak trend level difference in PPI between the two drugs $(\mathrm{F}(1,14)=3.21, p=.09)$ in the direction of greater PPI on the ketamine day. As expected, PPI increased as the interstimulus interval between the prepulse and pulse increased from 30 to 60 to $120 \mathrm{msec}(\mathrm{F}(2,28)=6.55, p<.005)$. See Figure 1 .

In order to minimize the effects of habituation, PPI was examined in Block 1 alone for the two test days. In this analysis, ketamine significantly increased PPI ( $p=$ .026). Again, PPI was greater in the trial types with longer interstimulus intervals $(p=.005)$ (Table 2).

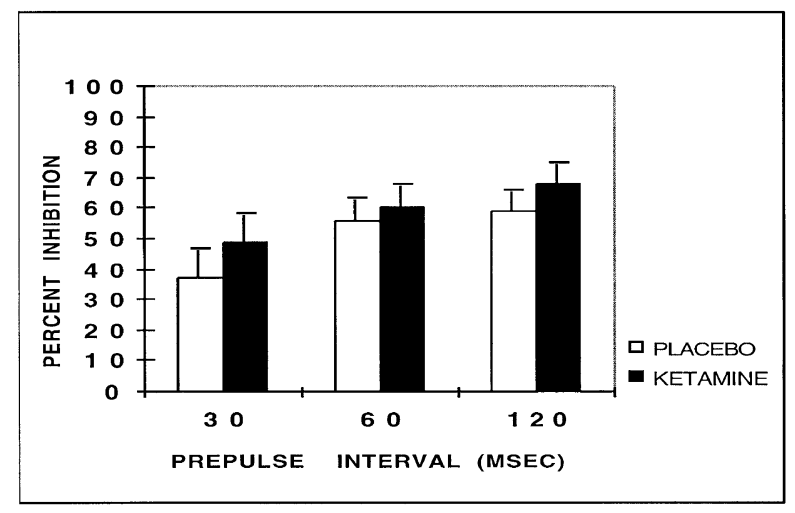

Figure 1. PPI for Block 1, Saline vs Ketamine Days (Mean \pm SEM). Prepulse interval refers to interstimulus intervals between prepulse and pulse-alone stimuli for the three trial types. ANOVA for Drug: $\mathrm{F}(1,14)=6.15, p<.026$.
In order to control for the possible confound which startle to pulse-alone may exert on PPI, a supplemental analysis by ANCOVA was performed. In this model, startle to pulse-alone amplitude for Block 1 was used as a covariate, with Condition (2 levels), and Trial Type (3 levels: 30, 60, and $120 \mathrm{msec}$ trials), were entered as within subject factors. The results of this ANCOVA model remained significant for Condition.

In order to rule out order effects, a separate analysis substituting Day for Drug as a factor was performed. There was no significant effect of Day when an ANOVA was performed on the three prepulse+pulse trial types for all three blocks $(\mathrm{F}(1,14)=.36, p=.56)$ or for Block 1 alone $(\mathrm{F}(1,14)=.01, p=.92)$.

Startle Latencies. Onset latency for all four trial types across the three blocks of each session was longer on ketamine than on saline, indicating that ketamine slowed the startle response (ANOVA: $p=.01$ ). On both drugs latency facilitation was apparent as expected, i.e. the $30 \mathrm{msec}$ prepulse trials shortened the onset latency compared to the latency to pulse-alone stimuli (ANOVA: $p=.0001)$ (Table 2). There was a significant effect of block $(\mathrm{F}(1,8)=7.0, p=.001)$ reflecting a relative lengthening of onset latency in blocks 2 and 3 in the $60 \mathrm{msec}$ and $120 \mathrm{msec}$ trial types.

The ANOVA for peak latency showed no difference between the two drug conditions $(p=.19)$. On both drugs peak latency showed latency facilitation (ANOVA: $p<.000$ )(Table 2). There was no significant block effect $(\mathrm{F}(1,8)=.33, p=.19)$ indicating that peak latencies did not change significantly across blocks.

Clinical Correlations. Ketamine's effects on total BPRS scores (at +50 min after the start of the infusion) correlated negatively with ketamine-induced changes in PPI for the $60 \mathrm{msec}$ trial type $(\mathrm{r}=-0.50, p<.05)$. PPI at the 30 and $120 \mathrm{msec}$ trial types varied negatively with total BPRS scores, although these relationships did not reach statistical significance. Ketamine-induced changes in total CADSS scores, as well as total scores on the Affect Rating Scale and the Abrams and Taylor Rating Scale, were not significantly related to ketamine's effects on PPI ( $r=0.42$ to -0.08 , n.s. for all comparisons). There were no significant correlations between any of the behavioral measures and onset and peak startle latencies.

\section{DISCUSSION}

The principal finding of this study is that ketamine infusion produced quite profound dissociative and negative symptoms, and less profound positive symptoms. These behavioral effects were not accompanied by a disruption of PPI. Rather, an enhancement of PPI was noted in some conditions of the startle paradigm. 
It is instructive to compare our clinical results with prior studies using comparable rating scales to document clinical effects of ketamine in normal controls. The study of Krystal et al. (1994) used modestly higher ketamine doses, and reported somewhat more robust positive and negative symptoms. Breier et al. (1997) also used a higher dosing schedule, and found somewhat more robust positive symptoms. Two additional studies (Malhotra et al. 1996; Krystal et al. 1999) used higher ketamine doses, although the resulting positive and negative symptom scores were very similar those of our study.

Ketamine infusion produced robust clinical effects which were reminiscent of but by no means identical to the symptoms commonly seen in schizophrenia. The subjects in our study experienced visual and auditory illusions rather than true hallucinations. Perceptual aberrations were more in the realm of visual, somatic, or proprioceptive distortions than is commonly seen in schizophrenics. There was a predominance of temporal and spatial distortions which, although not unheard of in schizophrenia, is not typical. Unlike what is commonly seen in schizophrenia, only a minority of our subjects ( 4 out of 16 or $25 \%$ ) gave evidence of frank suspiciousness.

The heightened perceptual sensitivity produced by ketamine appeared more similar to the psychotomimetic effects of psychedelic drugs than to stimulant induced psychoses. The "highness" experienced by our subjects was quite distinct from the subjective state endured by most schizophrenics. A few subjects reported feeling "a little bit drunk," likening the effects of ketamine to those of alcohol. These comments are in accord with recent work showing that ketamine produces ethanol-like subjective effects in detoxified alcoholics (Krystal et al. 1998). While most subjects described the ketamine experience as affectively "pleasant" or neutral, a few subjects experienced the sense of derealization and loss of control over thought processes as anxiety-provoking or frightening.

In contrast to the above symptom domains, the negative symptoms induced by ketamine were a much closer match to the characteristic negative symptoms of schizophrenia. Each one of our subjects showed an increase in the Affect Rating Scale and in the Abrams and Taylor scale during ketamine infusion. We observed blunting of affect, emotional withdrawal and impoverishment of speech, all of which closely mimicked the negative symptoms of schizophrenia. Yet our debriefing interviews, conducted after the last clinical effects of the infusion had waned, provided an important perspective on these negative symptoms. The subjects reported that, during the peak of the experience, they were either unable or uninterested in describing the drug effects, but found the experience extremely engrossing and intense. This inner state is likely to be dis- similar to that experienced by many of our chronic schizophrenic patients with profound negative symptoms, particularly those who report sitting for hours each day with few specific things on their minds.

The thought disorder elicited by ketamine was somewhat subtle, but concreteness on proverb interpretation was striking in some subjects and quite like the poor abstraction seen in schizophrenics. Our rating instruments only captured thought disorder in the Conceptual Disorganization item of the BPRS, which increased from $1 \pm 0$ at baseline to $1.7 \pm 1.0$ at +50 minutes on the ketamine day. Adler et al. (1998) have quantified thought disturbance more thoroughly by means of more sensitive instruments and found significant increases. Furthermore, the ketamine-induced thought disorder scores did not differ from scores in stable schizophrenics (Adler et al. 1999).

The clinical effects we elicited were not accompanied by impairments in PPI such as are seen in schizophrenia (Braff et al. 1992; Grillon et al. 1992; Bolino et al. 1994; Parwani et al. 2000). On the contrary, ketamine produced a significant enhancement of gating as indicated by increases in percent prepulse inhibition in Block 1 of the startle session. This is contrary to the disruptions in gating which have been reported in animals treated with PCP, ketamine, and MK-801 (Mansbach and Geyer 1989; Mansbach 1991; Keith et al. 1991; Swerdlow et al. 1993; Johansson et al. 1995; al-Amin and Schwartzkopf 1996; Swerdlow et al. 1998; de Bruin et al. 1999).

We doubt that the difference between our finding and that of the preclinical studies is simply a function of the timing of the prepulse paradigm relative to ketamine administration. The infusion lasted 60 minutes; prepulse testing was done at 30-45 minutes into the infusion, by which time the subjective and rating effects of the drug had reached robust and near maximum levels. Likewise, we doubt that it is due to inadequate dosing. As is evident from Table 1, changes in positive, negative, and dissociative symptoms were quite robust, indicating that our subjects attained clinically relevant plasma levels of ketamine.

There are several possible explanations for the discrepancy between our results and the preclinical findings in the literature. Firstly, the doses used in animal studies are much larger than what we used. We used $0.5 \mathrm{mg} / \mathrm{kg}$ infused over 60 minutes; whereas preclinical doses of ketamine have ranged from 5.6 to $36 \mathrm{mg} / \mathrm{kg}$ (Mansbach 1991; Johansson et al. 1995). The plasticity of PPI is due in part to modulatory inputs from the hippocampus (see Swerdlow et al. 1993 for review). As Grunze et al. (1996) have pointed out, there is NMDAdependent modulation of inhibitory intrinsic circuits in the CA1 region of the hippocampus. The sensitivity of these circuits to NMDA antagonism may be such that different doses of ketamine will result in a difference in 
the valence of hippocampal output and its consequent modulation of the startle circuitry. Alternately, humans and rodents may simply differ with respect to sensitivity to NMDA antagonism in the circuits which mediate sensory gating. However, dose response studies of ketamine effects on PPI in humans would be extremely useful to clarify the discrepancy between our results and those of preclinical studies which found gating disruption after ketamine (Mansbach and Geyer 1989; Mansbach 1991; Johansson et al. 1995; Swerdlow et al. 1998; de Bruin et al. 1999).

By way of comparison, the preclinical literature indicates that amphetamine disrupts PPI under some conditions, although the effect is dependent on dose, timing, parameters of testing, and rat strain (Davis 1988; Ott and Mandel 1995; Druhan et al. 1998; Zhang et al. 1998; Sills 1999; Kinney et al. 1999; Lacroix et al. 2000; Zhang et al. 2000). There is one study in the literature demonstrating amphetamine-induced disruption of PPI in humans (Hutchison and Swift 1999).

There is one prior report in the literature concerning effects of ketamine on PPI in humans (van Berckel et al. 1998). This group found that ketamine did not alter pulse-alone startle or PPI. However, their dose was 0.3 $\mathrm{mg} / \mathrm{kg}$ IV given over 135 minutes, whereas we gave 0.5 $\mathrm{mg} / \mathrm{kg}$ over 60 minutes. The clinical effects we observed were somewhat more robust than in the van Berckel study. Their startle paradigm only included prepulse + pulse trials with an interstimulus interval of $120 \mathrm{msec}$. We found the greatest difference between ketamine and saline in the $30 \mathrm{msec}$ prepulse trials. These methodological differences between our study and that of van Berckel et al. are possible explanations for our differing results.

Recent PET studies indicate that ketamine administration to normals increases metabolic activity in the frontal cortex, which increases correlate with ketamineinduced positive symptoms (Breier et al. 1997; Vollenweider et al. 1997a; Vollenweider et al. 1997b). Schizophrenia, and negative symptoms of schizophrenia in particular, have been associated with decreased frontal metabolic activity (Buchsbaum et al. 1982; Buchsbaum et al. 1990; Farkas et al. 1984; Wolkin et al. 1985; Cohen et al. 1987; Volkow et al. 1987; Wolkin et al. 1992; Siegel et al. 1993). However, this is not a consistent finding. In fact, studies in unmedicated acutely relapsed schizophrenics with robust positive symptoms have reported a hyperfrontal metabolic pattern (Volkow et al. 1986; Wiesel et al. 1987; Cleghorn et al. 1989; Ebmeier et al. 1993; Parellada et al. 1994). The extent to which ketamine administration is an accurate model of brain metabolic changes in schizophrenia needs further clarification.

Ketamine significantly prolonged onset latencies; peak latencies were nonsignificantly increased by ketamine. The significance of this finding is not clear, how- ever, it does not seem surprising that an anesthetic agent should produce such a slowing of response. Clinical studies of PPI have demonstrated increases in onset and peak tactile startle latencies in schizophrenia (Braff et al. 1992). Hence, although our findings regarding PPI contrast with the findings of impaired gating in schizophrenia, the prolonged onset latency with ketamine resembled that seen in schizophrenia.

The glutamatergic modulation of PPI is complex, and is dependent on methods of drug administration. Local infusions of NMDA and NMDA antagonists into the nucleus accumbens decrease and increase PPI respectively (Reijmers et al. 1995). Intra-accumbens infusion of both competitive NMDA receptor antagonists and glycine site antagonists cause disruptions of PPI (Kretschmer and Koch 1997), while both classes of drugs have no effects on PPI when administered systemically (Mansbach 1991; Bristow et al. 1995). Glutamatergic NMDA effects on PPI are thought not to be mediated through mesolimbic dopamine receptors, since disruption of PPI by NMDA antagonists are not reversed by D2 antagonists (Keith et al. 1991; Wan et al. 1996).

Ketamine interacts at several non-NMDA sites (Cohen et al. 1974; Smith et al. 1980; Smith et al. 1981; Øye et al. 1991) and hence it is possible that the effects of ketamine we observed were not related to its NMDA receptor activity. However, ketamine has higher affinity for NMDA receptors than for other sites (Øye et al. 1991; Javitt and Zukin 1991), and its behavioral effects are not blocked by drugs acting at these other sites (Byrd et al. 1987). In drug discrimination studies, ketamine produces PCP-like discriminative stimulus effects (Browne 1986; Brady and Balster 1982). For these reasons it is likely that the effects we observed are in fact largely due to NMDA sites of action.

In conclusion, ketamine administration to normal controls induced positive symptoms which were only a rough approximation of the positive symptoms of schizophrenia. Ketamine was a much better model for the negative symptoms of schizophrenia and for some aspects of schizophrenic thought disorder (particularly impoverishment and concreteness). These clinical effects were not accompanied by impaired gating as is seen in schizophrenia. Rather, in some stimulus conditions, ketamine improved PPI.

\section{ACKNOWLEDGMENTS}

This work was completed with the support of Pfizer, Inc. and the Veterans Administration New York Harbor Health Care System/New York Campus. Portions of this work were presented at the annual meeting of the American College of Neuropsychopharmacology, 1997. The assistance of Alena Kunzova and Shobhit Negi is gratefully acknowledged. 


\section{REFERENCES}

Abrams R, Taylor MA (1978): A rating scale for emotional blunting. Am J Psychiatry 135:226-229

Adler CM, Goldberg TM, Malhotra AK, Pickar D, Breier A (1998): Effects of ketamine on thought disorder, working memory and semantic memory in healthy volunteers. Biol Psychiatry 43:811-816

Adler CM, Malhotra AK, Elman I, Goldberg T, Egan M, Pickar D, Breier A (1999): Comparison of ketamineinduced thought disorder in healthy volunteers and thought disorder in schizophrenia. Am J Psychiatry 156:1646-1649

al-Amin HA, Schwartzkopf SB (1996): Effects of the PCP analog dizocilpine on sensory gating: potential relevance to clinical subtypes of schizophrenia. Biol Psychiatry 40(8):744-754

Allen RM, Young SJ (1978): Phencyclidine-induced psychosis. Am J Psychiatry 135(9):1081-1084

Andreasen NC (1979): Affective flattening and the criteria for schizophrenia. Am J Psychiatry 1366:944-947

Bakker CB, Amini FB (1961): Observations on the psychotomimetic effects of sernyl. Compr Psychiatry 2:269-280

Ban TA, Lohennz JJ, Lehmann HE (1961): Observations on the action of Sernyl - a new psychotropic drug. Can Psychiatr Assoc J 6:150-156

Bolino F, Di Michele V, Di Cicco L, Manna V, Daneluzzo E, Cassachia M (1994): Sensorimotor gating and habituation evoked by electrocutaneous stimulation in schizophrenia. Biol Psychiatry 36:670-679

Brady KT, Balster RL (1982): Discriminative stimulus properties of ketamine stereoisomers in phencyclidinetrained rats. Pharmacol Biochem Behav 17:291-295

Braff DL, Geyer MA (1990): Sensorimotor gating and schizophrenia. Arch Gen Psychiatry 47:181-188

Braff DL, Grillon C, Geyer MA (1992): Gating and habituation of the startle reflex in schizophrenic patients. Arch Gen Psychiatry 49:206-215

Braff DL, Stone C, Callaway E, Geyer M, Glick I, Bali L (1978): Prestimulus effects on human startle reflex in normals and schizophrenics. Psychophysiology 15:339-343

Breier A, Malhotra AK, Pinals DA, Weisenfeld NI, Pickar D (1997): Association of ketamine-induced psychosis with focal activation of the prefrontal cortex in healthy volunteers. Am J Psychiatry 154:805-811

Bremner JD, Krystal JH, Putnam FW, Southwick SM, Marmar C, Charney DS, Mazure CM (1998): Measurement of dissociative states with the Clinician-Administered Dissociative States Scale (CADSS). J Traumatic Stress 11:125-136

Bristow LJ, Landon L, Saywell KL, Tricklebank MD (1995): The glycine/NMDA receptor antagonist L-701,324 reverses isolation-induced deficits in prepulse inhibition in the rat. Psychopharmacology 118:230-232

Browne RG (1986): Discriminative stimulus properties of PCP mimetics. In Clouet D (ed), Phencyclidine: An update. Rockville, MD, NIDA Research Monograph 64

Buchsbaum MS, Ingvar DH, Kessler R (1982): Cerebral glucography with positron tomography: use in normal subjects and patients with schizophrenia. Arch Gen Psychiatry 39:251-259

Buchsbaum MS, Nuechterlein KH, Haier RJ, Wu J, Sicotte N, Hazlett E, Asarnow R, Potkin S, Guich S (1990): Glucose metabolic rate in normals and schizophrenics during the continuous performance test assessed by positron emission tomography. Br J Psychiatry 156:216-227

Byrd LD, Standish LJ, Howell LL (1987): Behavioral effects of phencyclidine and ketamine alone and in combination with other drugs. Eur J Pharmacol 144:331-341

Chapman LJ, Chapman JP, Raulin JP (1978): Body image aberration in schizophrenia. J Abnorm Psychol 87:399-407

Cleghorn JM, Garnett ES, Nahmias C, Firnau G, Brown GM, Kaplan R, Szechtman H, Szechtman B (1989): Increased frontal and reduced parietal glucose metabolism in acute untreated schizophrenia. Psychiatry Res 28:119-133

Cohen ML, Chan SL, Bhargava HN, Trevor AJ (1974): Inhibition of mammalian brain acetylcholinesterase by ketamine. Biochem Pharmacol 23:1647-1652

Cohen RM, Semple WE, Gross M, Nordahl TE, DeLisi LE, Holcomb HHY, King AC, Morihisa JM, Pickar D (1987): Dysfunction in a prefrontal substrate of sustained attention in schizophrenia. Life Sci 40:2031-2039

Davies BM, Beech HR (1960): The effect of 1-arylcyclohexylamine (Sernyl) on twelve normal volunteers. J Ment Sci 106:912-924

Davis M (1997): The neurophysiological basis of acoustic startle modulation: research on fear motivation and sensory gating. In Lang PJ, Simons RF, Balaban MT (eds), Attention and orienting: Sensory and motivational processes. Mahwah, New Jersey, Lawrence Erlbaum Associates, pp 69-96

Davis M (1988): Apomorphine, d-amphetamine, strychnine and yohimbine do not alter prepulse inhibition of the acoustic startle reflex. Psychopharmacology 95:151-156

de Bruin NMWJ, Ellenbrock BA, Cools AR, Coenen AML, van Luijtelaar ELJM (1999): Differential effects of ketamine on gating of auditory evoked potentials and prepulse inhibition in rats. Psychopharmacology 142:9-17

Deutsch SI, Mastropaolo J. Schwartz BL (1989): A "glutamatergic hypothesis" of schizophrenia. Clin Neuropharmacology 12:1-13

Druhan JP, Geyer MA, Valentin RJ (1998): Lack of sensitization to the effects of d-amphetamine and apomorphine on sensorimotor gating in rats. Psychopharmacology 135:296-304

Ebmeier KP, Blackwood DHR, Murray C, Souza V, Walker M, Doughall N, Moffoot APR, O'Carroll RE, Goodwin GM (1993): Single-photon emission computed tomography with ${ }^{99 m}$ Tc-Exametazime in unmedicated schizophrenic patients. Biol Psychiatry 33:487-495

Farkas T, Wolf AP, Jaeger J, Brodie JD, Christman DR, Fowler JS (1984): Regional brain glucose metabolism in chronic schizophrenia. A positron emission transaxial tomographic study. Arch Gen Psychiatry 41:293-300

Graham FK (1975): The more or less startling effects of weak prestimuli. Psychophysiology 12:238-248

Grillon C, Ameli R, Charney DS, Krystal J, Braff DL (1992): Startle gating deficits occur across prepulse intensities in schizophrenic patients. Biol Psychiatry 32:939-943 
Grunze HCR, Rainnie DG, Hasselmo ME, Barkai E et al. (1996): NMDA-dependent modulation of CA1 Local circuit inhibition. J Neurosci; 16(6):2034-2043

Guy W (1976): ECDEU Assessment Manual for Psychopharmacology. Washington DC, 1 US Department of Health, Education and Welfare, publication number ADM76-338

Hutchison KE, Swift R (1999): Effect of $d$-amphetamine on prepulse inhibition of the startle reflex in humans. Psychopharmacology 143:394-400

Itil T, Keskiner A, Kiremitici N, Holden JMC (1967): Effect of phencyclidine in chronic schizophrenia. Can J Psychiatry 12:209-212

Javitt DC, Zukin SR (1990): The role of excitatory amino acids in neuropsychiatric illness. J Neuropsychiatry and Clinical Neurosciences 2(1):44-52

Javitt DC, Zukin SR (1991): Recent advances in the phencyclidine model of schizophrenia. Am J Psychiatry 148:1301-1308

Johansson C, Jackson DM, Zhang J, Svensson L (1995): Prepulse inhibition of acoustic startle, a measure of sensorimotor gating: effects of antipsychotics and other agents in rats. Pharmacology Biochemistry and Behavior 52(4) 649-654

Keith VA, Mansbach RS, Geyer MA (1991): Failure of haloperidol to block the effects of phencyclidine and dizocilpine on prepulse inhibition of startle. Biol Psychiatry 30:557-566

Kim J, Kornhuber H, Schmid-Burgk W, Holzmuller B (1980): Low cerebrospinal fluid glutamate in schizophrenics and a new hypothesis on schizophrenia. Neurosci Lett 231:221-225

Kinney GG, Wilkinson LO, Saywell KL, Tricklebank MD (1999): Rat strain differences in the ability to disrupt sensorimotor gating are limited to the dopaminergic system, specific to prepulse inhibition, and unrelated to changes in startle amplitude or nucleus accumbens dopamine receptor sensitivity. J Neurosci 19:5644-5654

Kretschmer BD, Koch M (1997): Role of the strychnine insensitive glycine binding site in the nucleus accumbens and anterodorsal striatum in sensorimotor gating: a behavioral and microdialysis study. Psychopharmacology 130:131-138

Krystal JH, Karper LP, Seibyl JP, Freeman GK, Delancy R, Bremner JD, Heninger GR, Bowers MB, Charney DS (1994): Subanesthetic effects of the noncompetitive NMDA antagonist, ketamine, in humans: Psychotomimetic, perceptual, cognitive, and neuroendocrine responses. Arch Gen Psychiatry 51:199-214

Krystal JH, Petrakis IL, Webb E, Cooney NL, Karper LP, Namanworth S, Stetson P, Trevisan LA, Charney DS (1998): Dose-related ethanol-like effects of the NMDA antagonist, ketamine, in recently detoxified alcoholics. Arch Gen Psychiatry 55:354-360

Krystal JH, D'Souza DC, Karper LP, Bennett A, AbiDargham A, Abi-Saab D, Cassello K, Bowers MB, Vegso S, Heninger GR, Charney DS (1999): Interactive effects of subanesthetic ketamine and haloperidol in healthy humans. Psychopharmacology 145:193-204

Lacroix L, Broersen LM, Feldon J, Weiner I (2000): Effects of local infusions of dopaminergic drugs into the medial prefrontal cortex of rats on latent inhibition, prepulse inhibition and amphetamine induced activity. Behav Brain Res 107:111-121

Lahti AC, Koffel B, Laporte D, Tamminga CA (1995): Subanesthetic doses of ketamine stimulate psychosis in schizophrenia. Neuropsychopharmacology 13:9-19

Luby ED, Cohen BD, Rosenblaum G, Gottlieb JS, Kelly R (1959): Study of a new schizophrenomimetic drug-sernyl. Arch Neurol and Psychiatry 81:363-369

Malhotra AK, Pinals DA, Adler CM, Elman I, Clifton A, Pickar D, Breier A (1997): Ketamine-induced exacerbation of psychotic symptoms and cognitive impairment in neuroleptic-free schizophrenics. Neuropsychopharmacology 17(3):141-150

Malhotra AK, Pinals DA, Weingartner H, Sirocco K, Missar CD, Pickar D, Breier A (1996): NMDA receptor function and human cognition: The effects of Ketamine in healthy volunteers. Neuropsychopharmacology 14:301-307

Mansbach RS (1991): Effects of NMDA receptor ligands on sensorimotor gating in the rat. Eur J Pharmacology 202(1):61-66

Mansbach RS, Geyer MA (1989): Effects of phencyclidine and phencyclidine biologs on sensorimotor gating in the rat. Neuropsychopharmacology 2(4):299-308

McGhie A, Chapman J (1961): Disorders of attention and perception in early schizophrenia. Brit Journal of Medical Psychology 34:102-116

Olney JW, Farber NB (1995): Glutamate receptor dysfunction and schizophrenia. Arch Gen Psychiatry 52:998-1007

Ott DA, Mandel RJ (1995): Amphetamine sensitivity in open-field activity vs. the prepulse inhibition paradigm. Brain Res Bull 37:219-222

Øye I, Hustveit O, Maurset A, Moberg ER, Paulsen O, Skoglund LA (1991): The chiral forms of ketamine as probes for NMDA receptor functions in humans. In Kameyama T, Nabeshima T, Domino EF (eds), NMDA Receptor Related Agents: Biochemistry, Pharmacology and Behavior. Ann Arbor, MI, NPP Books, pp 381-389

Parellada E, Catafau AM, Bernardo M, Lomeña F, GonzálezMonclús E, Setoain J (1994): Prefrontal dysfunction in young acute neuroleptic-naive schizophrenic patients: a resting and activation SPECT study. Psychiatry Res Neuroimag 55:131-139

Parwani A, Duncan E, Bartlett E, Madonick S, Efferen TR, Rajan R, Sanfilipo M, Chappell PB, Chakravorty S, Gonzenbach S, Ko GN, Rotrosen JP (2000): Impaired prepulse inhibition of acoustic startle in schizophrenics. Biol Psychiatry 47:662-669

Reijmers LGJE, Vanderheyden PML, Peeters BWMM (1995): Changes in prepulse inhibition after local administration on NMDA receptor ligands in the core region of the rat nucleus accumbens. Eur J Pharmacol 272:131-138

Siegel BVJ, Buchsbaum MS, Bunney WEJ, Gottschalk LA, Haier RJR, Lohr JB, Lottenbery S, Najafi A, Nuechterlein KH, Potkin SG, Wu JC (1993): Cortical-striatal-thalamic circuits and brain glucose metabolic activity in 70 unmedicated male schizophrenic patients. Am J Psychiatry 150:1325-1336

Sills TL (1999): Amphetamine dose dependently disrupts prepulse inhibition of the acoustic startle response in rats within a narrow time window. Brain Res Bull 48:445-448 
Smith DJ, Azzaro AJ, Zaldivar SB, Palmer S, Lee HS (1981): Properties of the optical isomers and metabolites of ketamine on the high affinity transport and catabolism of monoamines. Neuropharmacology 20:391-396

Smith DJ, Pekoe GM, Martin LL, Coalgate B (1980): The interaction of ketamine with the opiate receptor. Life Sci 26:789-795

Swerdlow NR, Braff DL, Caine SB, Geyer MA (1993): Limbic cortico-striato-pallido-pontine: substrates of sensorimotor gating in animal models and psychiatric disorders. In Kalivas PW, Barnes CD (eds), Limbic Motor Circuits and Neuropsychiatry. London, CRC Press, pp 311-328

Swerdlow NR, Bakshi V, Waikar M, Taaid N, Geyer M (1998): Seroquel, clozapine and chlorpromazine restore sensorimotor gating in ketamine-treated rats. Psychopharmacology 140:75-80

van Berckel BNM, Orange B, van Ree JM, Verbaten MN, Kahn RS (1998): The effects of low dose ketamine on sensory gating, neuroendocrine secretion and behavior in healthy human subjects. Psychopharmacology 137:271-281

Volkow ND, Brodie JD, Wolf AP, Angrist B, Russell J, Cancro R (1986): Brain metabolism in patients with schizophrenia before and after acute neuroleptic administration. Neurosurg Psychiatry 49:1199-1202

Volkow ND, Wolf AP, van Gelder P, Brodie JD, Overall J, Cancro R, Gomez-Mont F (1987): Phenomenological correlates of metabolic activity in 18 patients with chronic schizophrenia. Am J Psychiatry 144:151-158

Vollenweider FX, Leenders KL, Scharfetter C, Antonini A, Macguire P, Missimer J, Angst J (1997a): Metabolic hyperfrontality and psychopathology in the ketamine model of psychosis using positron emission tomography (PET) and $\left[{ }^{18} \mathrm{~F}\right]$ fluorodeoxyglucose (FDG). Eur Neuropsycholpharmacol 7:9-24

Vollenweider FX, Leenders KL, Øye I, Hell D, Angst J (1997b): Differential psychopathology and patterns of cerebral glucose utilization produced by (S)- and (R)-ketamine in healthy volunteers using positron emission tomography (PET). Eur Neuropsycholpharmacol 7:25-38

Wan FJ, Caine SB, Swerdlow NR (1996): The ventral subiculum modulation of prepulse inhibition is not mediated via dopamine $D_{2}$ or nucleus accumbens non-NMDA glutamate receptor activity. Eur J Pharmacol 314:9-18

Wiesel FA, Wik G, Sjörgren I, Blomqvist G, Greitx T, StoneElander S (1987): Regional brain glucose metabolism in drug free schizophrenic patients and clinical correlates. Acta Psychiatr Scand 76:628-641

Wolkin A, Jaeger J, Brodie J, Wolf A, Fowler J, Rotrosen J, Gomez-Mont F, Cancro R (1985): Persistence of cerebral metabolic abnormalities in chronic schizophrenia as determined by positron emission tomography. Am J Psychiatry 142:564-571

Wolkin A, Sanfilipo M, Wolf AP, Angrist B, Brodie JD, Rotrosen J (1992): Negative symptoms and hypofrontality in chronic schizophrenia. Arch Gen Psychiatry 49:959-965

Zhang J, Engel JA, Söderpalm B, Svensson L (1998): Repeated administration of amphetamine induces sensitisation to its disruptive effect on prepulse inhibition in the rat. Psychopharmacol 135:401-406

Zhang J, Forkstam C, Engel JA, Svensson L (2000): Role of dopamine in prepulse inhibition of acoustic startle. Psychopharmacol 149:181-188 